\title{
The impact of the temperature of biodiesel from animal fats on nitrogen oxides emissions
}

\author{
Mirosław Czechlowski ${ }^{1, *}$, Weronika Gracz $^{2}$, Damian Marcinkowski ${ }^{2}$, Wojciech Golimowski ${ }^{3}$ \\ and Alina Kowalczyk-Juśko ${ }^{4}$ \\ ${ }^{1}$ Poznań University of Life Sciences, Faculty of Agronomy and Bioengineering, ul. Wojska Polskiego 28, 60-637 Poznań, Poland \\ ${ }^{2}$ Institute of Technology and Life Sciences, Department of Biomass processing Technologies, ul. Biskupińska 67, 60-463 Poznań, \\ Poland \\ ${ }^{3}$ Wroclaw University of Economics and Business, Department of Agricultural engineering and Quality Analysis, ul. Komandorska \\ 118/120, 53-345 Wrocław, Poland \\ ${ }^{4}$ University of Life Sciences in Lublin, Department of Environmental Engineering and Geodesy, Leszczyńskiego St. 7 , \\ 20-069, Poland
}

\begin{abstract}
The current results of $\mathrm{NO}_{\mathrm{x}}$ emission tests of diesel engines fuelled with unconventional biofuels are not unambiguous. Therefore, the aim of the study was to analyze the influence of temperature of methyl esters from animal fats (AFME) on the level of $\mathrm{NO}_{\mathrm{x}}$ emission. The test was carried out on an experimental stand equipped with a diesel engine with a power of $9.5 \mathrm{~kW}$. The engine was controlled by an electric generator from which the generated energy was fed into the electric network. The test was carried out in accordance with the D1 standard for power generators. As a result of the statistical analysis, significant differences were found for the values of average unit emissions of nitrogen oxides obtained for individual phases of D1 tests, i.e. engine loads amounting respectively to $50 \%, 75 \%$ and $100 \%$ of the nominal value of engine torque. On the basis of the test results, a significant influence of fuel temperature on $\mathrm{NO}_{\mathrm{x}}$ reduction can be found. Increase of fuel temperature by $50^{\circ} \mathrm{C}$ resulted in reduction of emissions by $6 \%$ on average.
\end{abstract}

\section{Introduction}

Gastronomy fats, otherwise known as used cooking fats (UCO), which are present in food production, are a valuable source of energy. It is estimated that $2.5 \mathrm{dm}^{3}$ of UCO per capita is generated annually in Europe [1]. Fats, due to their high calorific value of $38-42 \mathrm{MJ} \cdot \mathrm{kg}^{-1}$ and low viscosity, are a good raw material for fuel production [2].

In addition, a decrease in power output and a slight increase in nitrogen oxides $\left(\mathrm{NO}_{\mathrm{x}}\right)$ emissions were recorded [3][4]. Until recently, the development of combustion engines was focused on engine power and energy efficiency. Currently manufactured combustion engines must comply with rigorous exhaust emission standards. Due to the technological possibilities of using more and more effective exhaust gas filters, the emission of pollutants in the exhaust gas decreases. One of the first solutions to reduce NOx emissions to date was EGR exhaust gas recirculation systems [5]. Due to the introduction of increasingly restrictive regulations, the reduction of NOx emissions has been the subject of many ongoing studies. Currently, it has been found that catalysts for exhaust gas cleaning or biofuels used instead of conventional fuels are effective methods for reducing harmful gases [6][7].

Another solution is to modify the fuel or replace it with fuels from renewable sources. The introduction of water in the form of emulsions with the fuel or injected directly into the cylinder results in a significant reduction in nitrogen oxide emissions [8]. The replacement of diesel with rapeseed methyl esters RME of an engine equipped with NSR/DPNR/Oxidation catalysts resulted in increased NOx emissions [9]. This result was confirmed in other tests without NOx catalysts [10]. Moreover, the use of FAME type biofuels from various oils, also WCO used oils, resulted in an increase in NOx emission [11] [12]. When replacing diesel with rapeseed oil and hydrogenated HVO rapeseed oil, NOx emissions also increased with the increase in engine load. On the other hand, a decreasing share of $\mathrm{NO} 2 \cdot \mathrm{NOx}^{-1}$ [13][14][15].

The results of many scientific studies prove the possibility of using fats in their pure form as a fuel for diesel engines. Due to the need to adapt engines to this type of fuel, animal fats in particular, this solution has not been applied in the industry [16][17]. However, the subject of many studies to date has been the modification

\footnotetext{
Corresponding author: miroslaw.czechlowski@up.poznan.pl
} 
of animal fats to fuels with properties similar to those of diesel oil [18][19][20].

The use of fuels for diesel engines affects the specific consumption of fuel and the composition of exhaust gases emitted to the atmosphere [21]. The results of tests on a direct injection, single-cylinder engine at constant speed prove that the use of fuels from animal fats results in a significant reduction of carbon oxides and hydrocarbons in exhaust gases compared to diesel oil.

Similar results were obtained in a traction engine working on methyl esters from animal fats. The result was a reduction of $\mathrm{CO}, \mathrm{CH}$ and an increase in $\mathrm{NO}_{\mathrm{x}}$ emission. The opposite result was obtained when the engine was running on heated animal fat [22]. Results of other similar tests prove that there is no impact of biodiesel from animal fats on $\mathrm{NO}_{\mathrm{x}}$ emission levels [23]. Using fuels from neem oil, which is obtained as a result of transesterification reaction, $\mathrm{NO}_{\mathrm{x}}$ is significantly reduced in the emitted exhaust fumes [24].

On the basis of the analysis of the current state of knowledge of $\mathrm{NO}_{\mathrm{x}}$ emission levels at variable loads, inconsistencies of test results were found. The hypothesis that a rise in the temperature of biofuels from animal fats will result in a reduction in $\mathrm{NO}_{\mathrm{x}}$ has been investigated. Literature analyses show that the use of animal fats in pure form results in $\mathrm{NO}_{\mathrm{x}}$ reduction. Such fuels need to be heated to temperatures above $60^{\circ} \mathrm{C}$ because of their high viscosity. It is assumed that an increase in the temperature of methyl esters from animal fats will have a similar effect.

\section{Materials and methods}

Methyl esters from animal fats, more precisely pork lard, were used in the studies. Animal fats were transesterified at $60^{\circ} \mathrm{C}$ using homogeneous catalyst $2 \%(\mathrm{~m} / \mathrm{m}) \mathrm{KOH}$ and methanol in molar share 1:9. The experiment was carried out on an experimental stand consisting of: Yanmar 2TNV70-ASA diesel engine (Fig. 1), asynchronous engine, ATMX 2000 control and measurement system (Fig. 2), exhaust fumes were tested with VARIOplus Industrial analyzer.

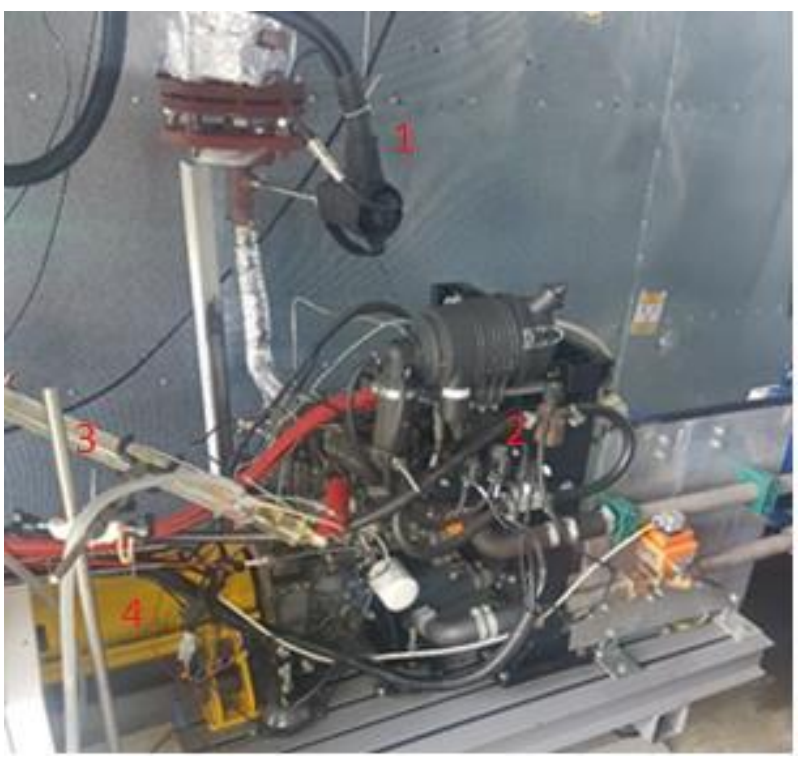

Fig. 1. Diesel engine Yanmar 2TNV70 on experimental stand Where: 1. Exhaust gas emission probe; 2. Diesel engine Yanmar; 3. Fuel heater; 4. Shaft connecting both engines

The measurement of exhaust parameters was about 1 meter from the exhaust manifold. The head of the measuring sensor was placed in the flue pipe. The probe was adapted to work in high dust, connected to the flue gas analyser by a heated pipe, then the gases did not condense. The flue gas composition was measured using a three-electrode electrochemical sensor. Analogue signal converted into a digital signal, values presented in ppm. The analyzer had a current calibration certificate. Additionally, the analyzer was equipped with a Pitot tube, which made it possible to measure the volume flow rate of emitted exhaust gases and a temperature sensor. Thanks to this, the control and measurement system of the exhaust gas analyser could automatically convert the emission expressed in ppm into mg$\mathrm{Nm}^{-3}$ of exhaust gas.

The 2TNV70 internal combustion engine was directly connected to the electrical shaft of the asynchronous motor. The combustion engine was loaded with an electric asynchronous motor. Electric energy from the asynhronic motor was input into the power grid by means of two inverters. In the experiment the power of the whole unit was measured, taking into account energy losses on mechanical components. Using the control system of the station it was possible to set the torque and the injection pump slat of the combustion engine. It was possible to precisely set the ordered engine loads.

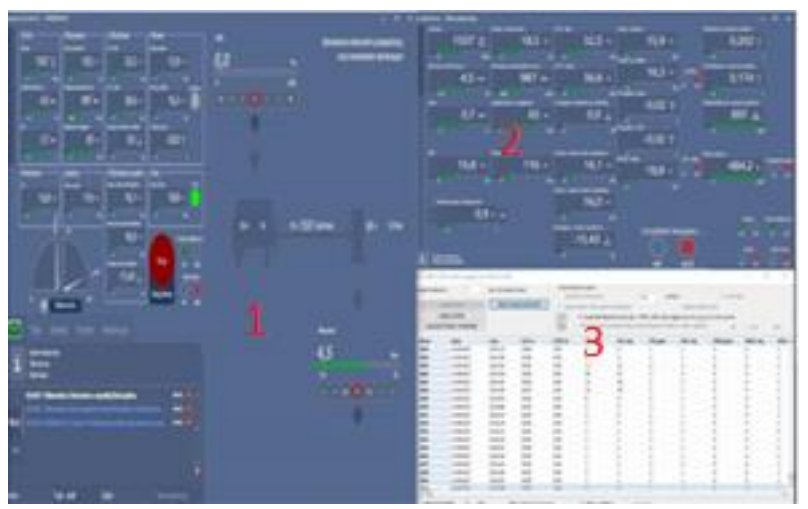

Fig. 2. Control panel of ATMX 2000 software for data logging and archiving. Where: 1. The possibility of changing 
parameters; 2. Recorded parameter data; 3. Recorded parameter of exhaust gas composition

The control of motor parameters was performed automatically by means of the control and measurement system after entering the set parameters. The load characteristics for this engine were first performed. In this way, the maximum torque that can be loaded on the motor without changing its speed was determined. The torque value was then changed to $75 \%$ of the value obtained in the first measurement and 50\%. The motor's torsion was controlled and corrected at all times.

Heating of the fuel was performed before the injection pump. A glass cooler was used to heat the fuel, which was connected to a thermostat. The thermostat was set to the water temperature so that the fuel temperature sensor at the injection pump was set to the value. During engine operation the fuel temperature did not change significantly.

Method of measurement. Before each measurement the engine oil temperature was $70^{\circ} \mathrm{C}$. Then the load was set and the heated fuel was fed. At constant parameters the engine worked for 10 minutes. After that time it was recorded for 3 minutes engine operation parameters.

The fuel temperature 20 and $70^{\circ} \mathrm{C}$ and the engine load at 50,75 and $100 \%$ are considered to be independent variables. The test was performed at a constant speed of $3000 \mathrm{rpm} \pm 1 \%$. The measurement was performed in accordance with procedure D1 of ISO 8178-4.

The torque values are the percentage values of the torque corresponding to the continuous rated power as defined in ISO 8528-1. To calculate the specific emissions from the test phase, the resulting average $\mathrm{NO}_{\mathrm{x}}$ concentration expressed in $\mathrm{mg} \cdot \mathrm{nm}^{-3}$ was converted into the specific $\mathrm{NO}_{\mathrm{x}}$ emission expressed in $\mathrm{g} \cdot \mathrm{kWh}^{-1}$. The formula below is used for this purpose for each phase of the D1 test.

$$
E_{N O_{x}}=\frac{\overline{S_{N O_{x}}} \cdot \dot{V}}{P \cdot 1000}
$$

where:

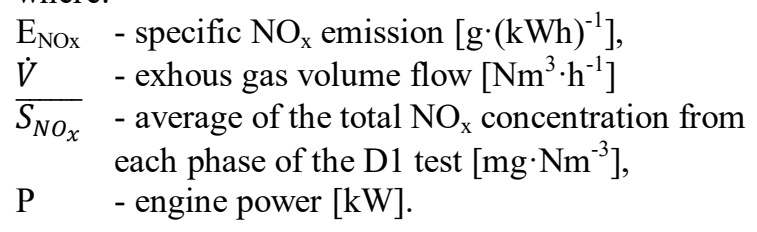

\section{Results}

Each measurement lasted 3 minutes, recording 20 measurement points. The average $\mathrm{NO}_{\mathrm{x}}$ emission values converted to unit values are presented in Fig. 3.

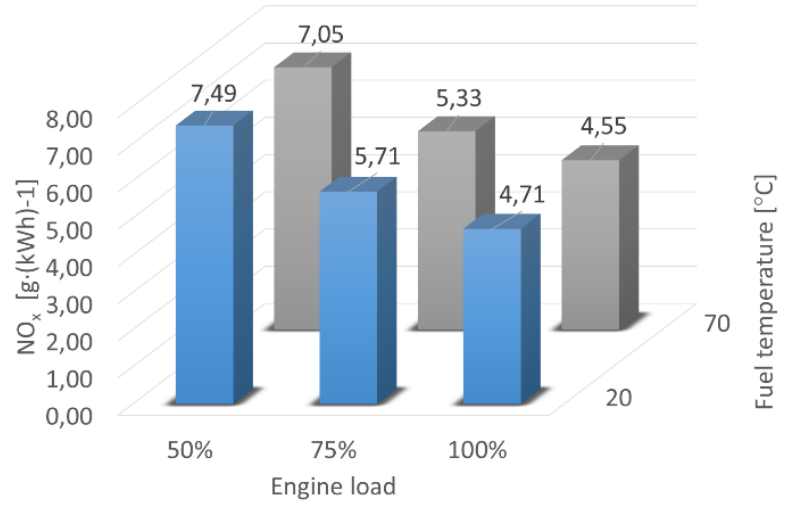

Fig. 3. Specific $\mathrm{NO}_{\mathrm{x}}$ emissions from the individual phases of D1test according to ISO 8178-4 standard depending on the engine feed fuel temperature.

On the basis of statistical data, the analysis of ANOWA one-way variance was performed in order to examine the significance of the influence of independent variables on the examined parameter. The hypothesis that fuel temperature has a significant influence on $\mathrm{NO}_{\mathrm{x}}$ emission was investigated. The statistical analysis shows that in all cases the results differ significantly, i.e. the hypothesis adopted is true. Based on the average values from the whole pool of results, it can also be concluded that the increase in temperature significantly affects the reduction of $\mathrm{NO}_{\mathrm{x}}$ emissions. The results are presented on Fig. 4.

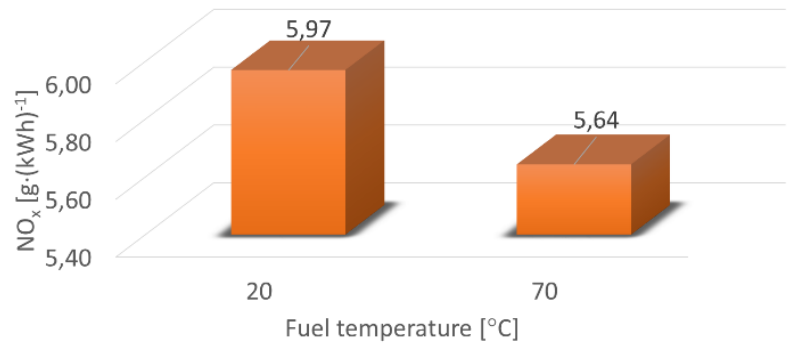

Fig. 4. Average $\mathrm{NO}_{\mathrm{x}}$ emission from test $\mathrm{D} 1$ according to ISO 8178-4 standard depending on the temperature of the fuel feeding the engine

\section{Conclusion}

The results obtained allow us to formulate the following conclusions:

The increase in fuel temperature by $50^{\circ} \mathrm{C}$ resulted in a significant reduction in $\mathrm{NO}_{\mathrm{x}}$ emissions for all phases of the D1 test, implemented in accordance with ISO 81784.

The increase in engine load from 50 to $100 \%$ results in monotonous $\mathrm{NO}_{\mathrm{x}}$ emission reductions for all phases of test D1. The change in engine load within the abovementioned range results in a reduction of $36 \%$ in $\mathrm{NO}_{\mathrm{x}}$ emissions.

Increasing the fuel temperature by $50^{\circ} \mathrm{C}$ resulted in a reduction in the specific $\mathrm{NO}_{\mathrm{x}}$ emission by $6 \%$ on average. 
The fuel in the engine is burned in two phases. The first one is the dynamic heat release and then the fuel is burned. An increase in the fuel temperature can cause a rise in the temperature in the combustion chamber. A higher temperature in the long combustion phase of the engine may cause the breakdown of nitrogen oxides produced in the first phase.

\section{Acknowledgements}

Publication is funded by the Polish National Agency for Academic Exchange under the International Academic Partnerships Programme from the project „Organization of the $9^{\text {th }}$ International Scientific and Technical Conference entitled Environmental Engineering, Photogrammetry, Geoinformatics - Modern Technologies and Development Perspectives".

\section{References}

[1] T. Wallace, D. Gibbons, M. O’Dwyer, and T. P. Curran, "International evolution of fat, oil and grease (FOG) waste management - A review," $J$. Environ. Manage., vol. 187, pp. 424-435, Feb. 2017.

[2] G. Goga, B. Singh Chauhan, S. Kumar Mahla, H. Muk Cho, A. Dhir, and H. Chang Lim, "Properties and characteristics of various materials used as biofuels: A review," Mater. Today Proc., vol. 5, no. 14, pp. 28438-28445, Jan. 2018.

[3] S. Awad, K. Loubar, and M. Tazerout, "Experimental investigation on the combustion, performance and pollutant emissions of biodiesel from animal fat residues on a direct injection diesel engine," Energy, vol. 69, pp. 826-836, May 2014.

[4] P. G. Blakeman, A. F. Chiffey, P. R. Phillips, M. V. Twigg, and A. P. Walker, "Developments in diesel emission aftertreatment technology," $S A E$ Tech. Pap., 2003.

[5] D. A. Kouremenos, D. T. Hountalas, and K. B. Binder, "The effect of EGR on the performance and pollutant emissions of heavy duty diesel engines using constant and variable AFR," $S A E$ Tech. Pap., vol. 2001, no. 724, 2001.

[6] A. M. Hochhauser, "Review of prior studies of fuel effects on vehicle emissions," SAE Tech. Pap., vol. 2, no. 1, pp. 541-567, 2009.

[7] T. Johnson, "Vehicular Emissions in Review," SAE Int. J. Engines, vol. 7, no. 3, 2014.

[8] D. T. Hountalas, G. C. Mavropoulos, T. C. Zannis, and S. D. Mamalis, "Use of water emulsion and intake water injection as NOx reduction techniques for heavy duty diesel engines," SAE Tech. Pap., vol. 2006, no. 724, 2006.

[9] D. Kawano, H. Ishii, Y. Goto, A. Noda, and Y. Aoyagi, "Application of biodiesel fuel to modern diesel engine," SAE Tech. Pap., no. 724, 2006.

[10] M. K. Veltman, P. K. Karra, and S. C. Kong, "Effects of biodiesel blends on emissions in low temperature diesel combustion," SAE Tech. Pap., 2009.

[11] K. Okamoto et al., "Impact study of high biodiesel blends on exhaust emissions to advanced aftertreatment systems," SAE Tech. Pap., 2010.

[12] N. Gysel, G. Karavalakis, T. Durbin, D. Schmitz, and A. Cho, "Emissions and redox activity of biodiesel blends obtained from different feedstocks from a heavy-duty vehicle equipped with DPF/SCR aftertreatment and a heavy-duty vehicle without control aftertreatment," $S A E$ Tech. Pap., vol. 1, 2014.

[13] J. Czerwinski, Y. Zimmerli, M. Meyer, and M. Kasper, "A modern HD-diesel engine with rapeseed oil, DPF and SCR," SAE Tech. Pap., vol. 2008, no. 724, pp. 776-790, 2008.

[14] N. Mizushima, S. Sato, D. Kawano, A. Saito, and Y. Takada, "A Study on NOx Emission Characteristics When Using Biomass-derived Diesel Alternative Fuels," SAE Int. J. Fuels Lubr., vol. 5, no. 2, pp. 892-899, 2012.

[15] Y. Wu, J. Ferns, H. Li, and G. Andrews, "Investigation of Combustion and Emission Performance of Hydrogenated Vegetable Oil (HVO) Diesel," SAE Int. J. Fuels Lubr., vol. 10, no. 3, 2017.

[16] M. Senthil Kumar, A. Kerihuel, J. Bellettre, and M. Tazerout, "Experimental investigations on the use of preheated animal fat as fuel in a compression ignition engine," Renew. Energy, vol. 30, no. 9, pp. 1443-1456, Jul. 2005.

[17] W. Golimowski, P. Pasyniuk, and W. A. Berger, "Common rail diesel tractor engine performance running on pure plant oil," Fuel, vol. 103, pp. 227-231, Jan. 2013.

[18] W. Golimowski, W. A. Berger, P. Pasyniuk, W. Rzeźnik, M. Czechlowski, and A. Koniuszy, "Biofuel parameter dependence on waste fats" fatty acids profile," Fuel, vol. 197, pp. 482-487, Jun. 2017.

[19] P. Suchamalawong, S. Pengnarapat, P. Reubroycharoen, and T. Vitidsant, "Biofuel preparation from waste chicken fat using coal fly ash as a catalyst: Optimization and kinetics study in a batch reactor," J. Environ. Chem. Eng., vol. 7, no. 3, p. 103155, Jun. 2019.

[20] S. M. Safieddin Ardebili and A. Khademalrasoul, "An analysis of liquid-biofuel production potential from agricultural residues and animal fat (case study: Khuzestan Province)," J. Clean. Prod., vol. 204, pp. 819831, Dec. 2018.

[21] A. Domínguez-Sáez, G. A. Rattá, and C. C. Barrios, "Prediction of exhaust emission in 
transient conditions of a diesel engine fueled with animal fat using Artificial Neural Network and Symbolic Regression," Energy, vol. 149, pp. 675-683, Apr. 2018.

[22] A. Kleinová, I. Vailing, J. Lábaj, J. Mikulec, and J. Cvengroš, "Vegetable oils and animal fats as alternative fuels for diesel engines with dual fuel operation," Fuel Process. Technol., vol. 92, no. 10, pp. 1980-1986, Oct. 2011.

[23] C. C. Barrios, A. Domínguez-Sáez, C. Martín, and P. Álvarez, "Effects of animal fat based biodiesel on a TDI diesel engine performance, combustion characteristics and particle number and size distribution emissions," Fuel, vol. 117, pp. 618-623, Jan. 2014.

[24] Ranjith, V. Velmurugan, and S.

Thanikaikarasan, "Prediction of Exhaust Gas Emission characteristics using Neem oil blended bio- diesel in diesel engine," Mater. Today Proc., Sep. 2019. 